Portland State University

PDXScholar

$6-2014$

\title{
Local Vibrational Modes Competitions in Mn-Doped ZnO Epitaxial Films with Tunable Ferromagnetism
}

\author{
Qiang Cao \\ Shandong University \\ Maoxiang Fu \\ Shandong University \\ Guolei Liu \\ Shandong University \\ Huaijin Zhang \\ Shandong University \\ Shishen Yan \\ Shandong University
}

See next page for additional authors

Follow this and additional works at: https://pdxscholar.library.pdx.edu/mengin_fac

Part of the Materials Science and Engineering Commons, and the Mechanical Engineering Commons Let us know how access to this document benefits you.

\section{Citation Details}

Cao, Q., Fu, M., Liu, G., Zhang, H., Yan, S., Chen, Y., ... \& Jiao, J. (2014). Local vibrational modes competitions in Mn-doped $\mathrm{ZnO}$ epitaxial films with tunable ferromagnetism. Journal of Applied Physics, 115(24), 243906.

This Article is brought to you for free and open access. It has been accepted for inclusion in Mechanical and Materials Engineering Faculty Publications and Presentations by an authorized administrator of PDXScholar. Please contact us if we can make this document more accessible: pdxscholar@pdx.edu. 


\section{Authors}

Qiang Cao, Maoxiang Fu, Guolei Liu, Huaijin Zhang, Shishen Yan, Yanxue Chen, Liangmo Mei, and Jun Jiao 


\title{
Local vibrational modes competitions in Mn-doped $\mathrm{ZnO}$ epitaxial films with tunable ferromagnetism
}

\author{
Qiang Cao, ${ }^{1,2}$ Maoxiang Fu, ${ }^{1}$ Guolei Liu, ${ }^{1, a)}$ Huaijin Zhang, ${ }^{1}$ Shishen Yan, ${ }^{1}$ Yanxue Chen, ${ }^{1}$ \\ Liangmo Mei, ${ }^{1}$ and Jun Jiao ${ }^{3}$ \\ ${ }^{1}$ National Key Laboratory of Crystal Materials and School of Physics, Shandong University, \\ Jinan, Shandong 250100, People's Republic of China \\ ${ }^{2}$ School of Physics and Engineering, Qufu Normal University, Qufu, Shandong 273165 , \\ People's Republic of China \\ ${ }^{3}$ Department of Mechanical and Materials Engineering, Portland State University, \\ P.O. Box 751, Portland, Oregon 97207-0751, USA
}

(Received 5 May 2014; accepted 14 June 2014; published online 26 June 2014)

\begin{abstract}
We reported spectroscopic investigations of high quality $\mathrm{Mn}$-doped $\mathrm{ZnO}(\mathrm{ZnMnO})$ films grown by oxygen plasma-assisted molecular beam epitaxy. Raman scattering spectra revealed two local vibrational modes (LVMs) associated with Mn dopants at 523 and $712 \mathrm{~cm}^{-1}$. The LVMs and magnetic properties of $\mathrm{ZnMnO}$ films can be synchronously modulated by post annealing processing or by introducing tiny Co. The relative intensity of two LVMs clearly shows competitions arising from uncompensated acceptor and donor defects competition for ferromagnetic and nonmagnetic films. The experimental results indicated that LVM at $523 \mathrm{~cm}^{-1}$ is attributed to $\mathrm{Mn}$-(Zinc-vacancy) complexes, while LVM at $712 \mathrm{~cm}^{-1}$ is attributed to Mn-(Oxygen-vacancy) complexes. (C) 2014 AIP Publishing LLC.

[http://dx.doi.org/10.1063/1.4885735]
\end{abstract}

\section{INTRODUCTION}

$\mathrm{ZnO}$ and related compounds have been receiving much attention over the past decades due to many existing or emerging applications in optoelectronics, transparent electronics, and spintronics. ${ }^{1}$ To optimize their applications, it is essential to understand the behavior of defects since most of the properties depend in one way or another on the defects that are present in the material. Recently, a growing number of theoretical and experimental works have given an indication that defects play a primary role in mediating the ferromagnetism of transition-metal-doped $\mathrm{ZnO}^{2,3}$ In the case of Mn-doped $\mathrm{ZnO}(\mathrm{ZnMnO})$, although a large number of works on defect induced ferromagnetism are available in literature, an experimental evidence of direct link between defects and magnetic properties is still lacking. To clarify the detailed picture of defects in tailoring magnetic properties, it is very helpful to perform spectroscopic investigations on defects in materials, whose magnetic properties can be modulated. In particular, the characterization of local vibration of defects can yield very valuable information on the microstructure and nature of defects in materials, which has been demonstrated in Mg-doped and ion-implanted GaN. ${ }^{4,5}$ However, no detailed investigations on local vibrational modes (LVMs) of defects and dopants have been reported, and the assignment of the LVMs in ZnMnO still remains a controversy. ${ }^{6,7}$

In this work, we presented spectroscopic investigations on $\mathrm{ZnMnO}$ epitaxial films with tunable ferromagnetism. The preparation of high-quality epitaxial films can availably avoid grain boundaries $^{8}$ or magnetic secondary phase, ${ }^{9}$ which have great impact on the characterization of Raman scattering and

\footnotetext{
a) Author to whom correspondence should be addressed. Electronic mail: liu-guolei@sdu.edu.cn
}

magnetic properties. The ferromagnetism in $\mathrm{ZnMnO}$ films can be modulated by either thermal annealing processing or introducing tiny Co. Raman spectra revealed two LVMs at 523 and $712 \mathrm{~cm}^{-1}$, which are related not only to Mn dopants but also to defects. The experimental results obtained from magnetic, photoluminescence, and Raman measurements indicated that LVM at $523 \mathrm{~cm}^{-1}$ is attributed to $\mathrm{Mn}$-(Zinc-vacancy) complexes, while the LVM at $712 \mathrm{~cm}^{-1}$ is attributed to $\mathrm{Mn}-$ (Oxygen-vacancy) complexes.

\section{EXPERIMENTAL}

Three sets of samples were prepared and investigated: (1) as-prepared $\mathrm{Zn}_{1-\mathrm{x}} \mathrm{Mn}_{\mathrm{x}} \mathrm{O}$ epitaxial films with $\mathrm{Mn}$ content $\mathrm{x}=0,0.01,0.03$, and 0.05. (2) Post-annealed $\mathrm{Zn}_{1-\mathrm{x}} \mathrm{Mn}_{\mathrm{x}} \mathrm{O}$ $(\mathrm{x}=0,0.05)$ films. To compare the annealing effects, the sample at size of $5 \times 10 \mathrm{~mm}^{2}$ was cut into 4 pieces. The first piece was annealed at $800^{\circ} \mathrm{C}$ under ultra high vacuum (UHV) for an hour (UHV-anneal), the second one was annealed at $800^{\circ} \mathrm{C}$ for an hour under UHV with irradiation of atomic oxygen flux by using an Oxford plasma source (O-anneal), and third one was annealed at $800^{\circ} \mathrm{C}$ for an hour under UHV with irradiation of $\mathrm{Zn}$ flux by using a $\mathrm{Zn}$ k-cell (Zn-anneal), respectively. (3) $\mathrm{Zn}_{0.99-\mathrm{x}} \mathrm{Co}_{0.01} \mathrm{Mn}_{\mathrm{x}} \mathrm{O}$ epitaxial films with $\mathrm{x}=0,0.01,0.03$, and 0.05 .

High quality $\mathrm{ZnMnO}$ films were grown on $\mathrm{Al}_{2} \mathrm{O}_{3}(0001)$ substrates by oxygen plasma-assisted molecular beam epitaxy (OPAMBE). The growth procedure has been described elsewhere. ${ }^{10}$ The film growth was monitored by real time Reflection High Energy Electron Diffraction (RHEED). The crystal structure of epitaxial films was characterized by high resolution X-ray diffraction (HRXRD). The magnetic field dependent magnetization $(\mathrm{M}-\mathrm{H})$ curves were measured by an alternatively gradient magnetometer (AGM) at room 
temperature and by a superconductivity quantum interference device at low temperature. The Photoluminescence (PL) spectra were excited by a $325 \mathrm{~nm} \mathrm{He}-\mathrm{Cd}$ laser. The radiation of $514.53 \mathrm{~nm}$ from an $\mathrm{Ar}^{+}$ion laser with a total power of $10 \mathrm{~mW}$ was used as an excitation source, and it was focused to $\sim 2 \mu \mathrm{m}$ in diameter on the samples. The line positions were determined using a triple-grating monochromator with resolution better than $1 \mathrm{~cm}^{-1}$ in the wavenumber range from 200 to $1000 \mathrm{~cm}^{-1}$.

\section{RESULTS AND DISCUSSION}

\section{A. Epitaxial growth and Structural characterization}

Fig. 1(a) shows the RHEED patterns for $\mathrm{ZnO}$ buffer layer, $\mathrm{Zn}_{0.95} \mathrm{Co}_{0.01} \mathrm{O}, \mathrm{Zn}_{0.95} \mathrm{Mn}_{0.05} \mathrm{O}$, and $\mathrm{Zn}_{0.94} \mathrm{Co}_{0.01} \mathrm{Mn}_{0.05} \mathrm{O}$ epilayers. The $\mathrm{ZnO} / \mathrm{Al}_{2} \mathrm{O}_{3}(0001)$ buffer layer has stripe RHEED pattern, which displays layer by layer growth mode and smooth surface morphology. The elongated diffraction spots in $\mathrm{Mn}$ (or/and $\mathrm{Co}$ ) doped $\mathrm{ZnO}$ films indicated a rougher

(a)
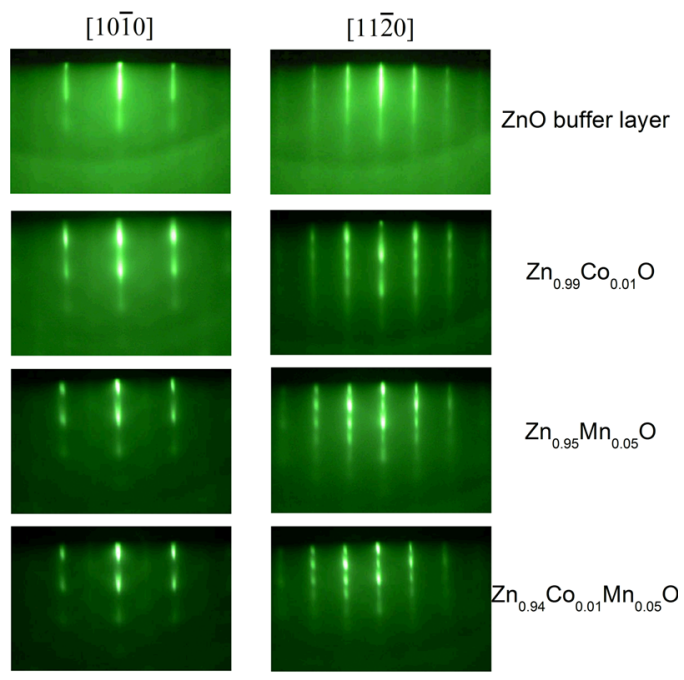

(b)

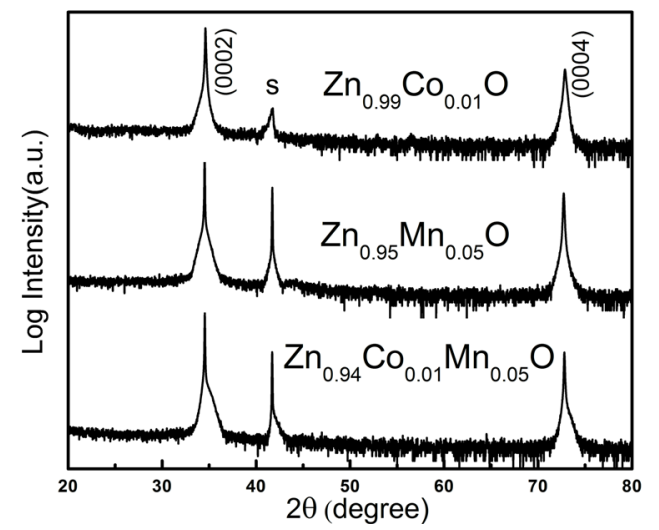

FIG. 1. (a) RHEED patterns for $\mathrm{ZnO}$ buffer layer, $\mathrm{Zn}_{0.95} \mathrm{Co}_{0.01} \mathrm{O}$, $\mathrm{Zn}_{0.95} \mathrm{Mn}_{0.05} \mathrm{O}$, and $\mathrm{Zn}_{0.94} \mathrm{Co}_{0.01} \mathrm{Mn}_{0.05} \mathrm{O}$ epilayers with the electron beam along $\mathrm{ZnO}[10 \overline{1} 0]$ (left column) and [112̄0] (right column) directions. (b) HRXRD $\theta-2 \theta$ scans for $\mathrm{Zn}_{0.95} \mathrm{Co}_{0.01} \mathrm{O}, \mathrm{Zn}_{0.95} \mathrm{Mn}_{0.05} \mathrm{O}$, and $\mathrm{Zn}_{0.94} \mathrm{Co}_{0.01}$ $\mathrm{Mn}_{0.05} \mathrm{O}$ films. The peak from the sapphire substrate is denoted $\mathrm{S}$. surface morphology, which were caused by the doping induced distortion when part of the $\mathrm{Zn}$ cations was substituted by $\mathrm{Mn}$ or/and Co cations. Since RHEED is very sensitive to surface structure during film growth, no polycrystalline rings or surface structure other than $\mathrm{ZnO}$ were detected in doped $\mathrm{ZnO}$ films. Fig. 1(b) shows the HRXRD $\theta-2 \theta$ scans for $\mathrm{Zn}_{0.95} \mathrm{Co}_{0.01} \mathrm{O}, \mathrm{Zn}_{0.95} \mathrm{Mn}_{0.05} \mathrm{O}$, and $\mathrm{Zn}_{0.94} \mathrm{Co}_{0.01} \mathrm{Mn}_{0.05} \mathrm{O}$ films, only (0002) and (0004) peaks of wurtzite lattice were detected, which indicate all the doped films exhibit a single crystalline characteristic without any second phase. Furthermore, a full-width at half maximum of $0.295^{\circ}$ in $\omega$-rocking curves indicates high structural perfection in $\mathrm{Zn}_{0.95} \mathrm{Mn}_{0.05} \mathrm{O}$ film.

\section{B. Raman spectra of as-prepared films}

Fig. 2 shows the Raman spectra of as-prepared $\mathrm{Zn}_{1-}$ ${ }_{\mathrm{x}} \mathrm{Mn}_{\mathrm{x}} \mathrm{O}$ epitaxial films with $\mathrm{Mn}$ content $\mathrm{x}=0,0.01,0.03$, and 0.05 . For undoped $\mathrm{ZnO}$ film, the dominated $\mathrm{E}_{2 \text { (high) }}$ mode at $437\left(\mathrm{I}_{2}\right) \mathrm{cm}^{-1}$ indicates an excellent crystalline of wurtzite $\mathrm{ZnO}$ lattice. In addition, there are four Raman-active vibration modes at $276\left(\mathrm{I}_{1}\right), 508\left(\mathrm{I}_{4}\right), 580\left(\mathrm{I}_{6}\right)$, and $642\left(\mathrm{I}_{7}\right) \mathrm{cm}^{-1}$, which are assigned to the $\mathrm{B}_{1 \text { (low) }}, 2 \mathrm{~B}_{1 \text { (low) }}, \mathrm{B}_{1 \text { (high), and }}$ $\mathrm{TA}+\mathrm{B}_{1 \text { (high) }}$ symmetric phonon modes, ${ }^{11-13}$ respectively. The silent $\mathrm{B}_{1}$ modes and the second-order modes observed in pure $\mathrm{ZnO}$ film are attributed to disorder-activated Raman scattering caused by growth conditions. For as-prepared $\mathrm{Zn}_{1-}$ ${ }_{\mathrm{x}} \mathrm{Mn}_{\mathrm{x}} \mathrm{O}$ films, with increasing $\mathrm{Mn}$ content, the intensity of disorder-activated phonon modes at $276\left(\mathrm{I}_{1}\right), 472\left(\mathrm{I}_{3}\right), 580$ $\left(\mathrm{I}_{6}\right)$, and $642\left(\mathrm{I}_{7}\right) \mathrm{cm}^{-1}$ enhances whereas the intensity of $\mathrm{E}_{2 \text { (high) }}\left(\mathrm{I}_{2}\right)$ mode almost remains constant, which suggests that $\mathrm{Mn}$ ions substituted into wurtzite $\mathrm{ZnO}$ without destroying the host lattice. It should be noted that there are two addition modes (AMs): a peak at $712\left(\mathrm{I}_{8}\right) \mathrm{cm}^{-1}$ and a broad peak around $523\left(\mathrm{I}_{5}\right) \mathrm{cm}^{-1}$. The mode around $523 \mathrm{~cm}^{-1}$ has been observed in most $\mathrm{Zn}_{1-\mathrm{x}} \mathrm{Mn}_{\mathrm{x}} \mathrm{O}$ materials, but the assignment of this mode still remains a controversy. ${ }^{6,7,14}$ The mode $\mathrm{I}_{8}$ has not yet been reported in literature. It cannot be attributed to secondary phases, such as $\mathrm{ZnMn}_{2} \mathrm{O}_{4},{ }^{15} \mathrm{MnO}_{2},{ }^{16}$ $\mathrm{Mn}_{2} \mathrm{O}_{3},{ }^{16,17}$ and $\mathrm{Mn}_{3} \mathrm{O}_{4} \cdot{ }^{17}$ It is found that the AMs $\mathrm{I}_{5}$ and $\mathrm{I}_{8}$ are absent in pure $\mathrm{ZnO}$ films and $\mathrm{Co}$ doped $\mathrm{ZnO}$ films under

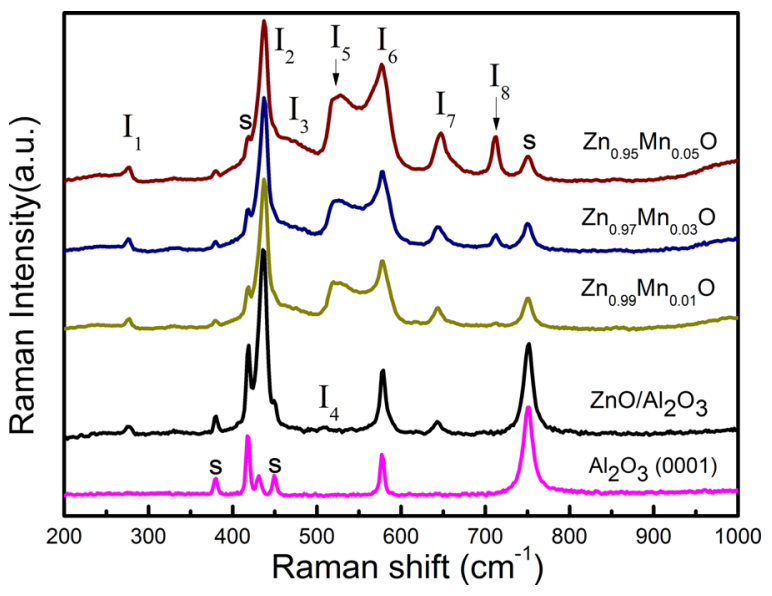

FIG. 2. Raman spectra of as-prepared $\mathrm{Zn}_{1-\mathrm{x}} \mathrm{Mn}_{\mathrm{x}} \mathrm{O}$ epitaxial films with $\mathrm{Mn}$ content $\mathrm{x}=0,0.01,0.03$, and 0.05 , as well as the referenced $\mathrm{Al}_{2} \mathrm{O}_{3}(0001)$ substrate. The vibration modes from substrate were marked by $\mathrm{S}$. 
the same growth conditions. ${ }^{18}$ But both of them are observed in ( $\mathrm{Mn}, \mathrm{Co}$ ) codoped $\mathrm{ZnO}$ films (Fig. 6). Further, the intensity of $A M s I_{5}$ and $I_{8}$ both increases with $\mathrm{Mn}$ content. Therefore, the AMs $I_{5}$ and $I_{8}$ are LVMs associated with Mn ions in $\mathrm{ZnO}$ lattice.

\section{Effects of post-annealing}

Fig. 3(a) shows the M-H curves for as-prepared, postanneal $\mathrm{Zn}_{0.95} \mathrm{Mn}_{0.05} \mathrm{O}$ films. As-prepared $\mathrm{Zn}_{1-\mathrm{x}} \mathrm{Mn}_{\mathrm{x}} \mathrm{O}$ films are paramagnetic (PM) from room temperature until down to $5 \mathrm{~K}$, which is consistent with the results reported in highquality samples. ${ }^{19,20}$ The Zn-anneal and UHV-anneal samples are both paramagnetic, whereas the O-anneal sample exhibits ferromagnetism (FM) at room temperature, which is clearly illustrated in Fig. 3(a). The surface and crystal structure after annealing treatments was re-checked by RHEED and HRXRD, which indicated that the O-anneal process improves the surface roughness and crystal quality of the samples. In addition, compared experiments using undoped $\mathrm{ZnO}$ films did not show ferromagnetism under any conditions. Fig. 3(b) shows the low temperature near-band PL spectra for annealed samples. Four PL peaks at 3.376, 3.357, 3.321 , and $3.316 \mathrm{eV}$ are observed, which correspond to
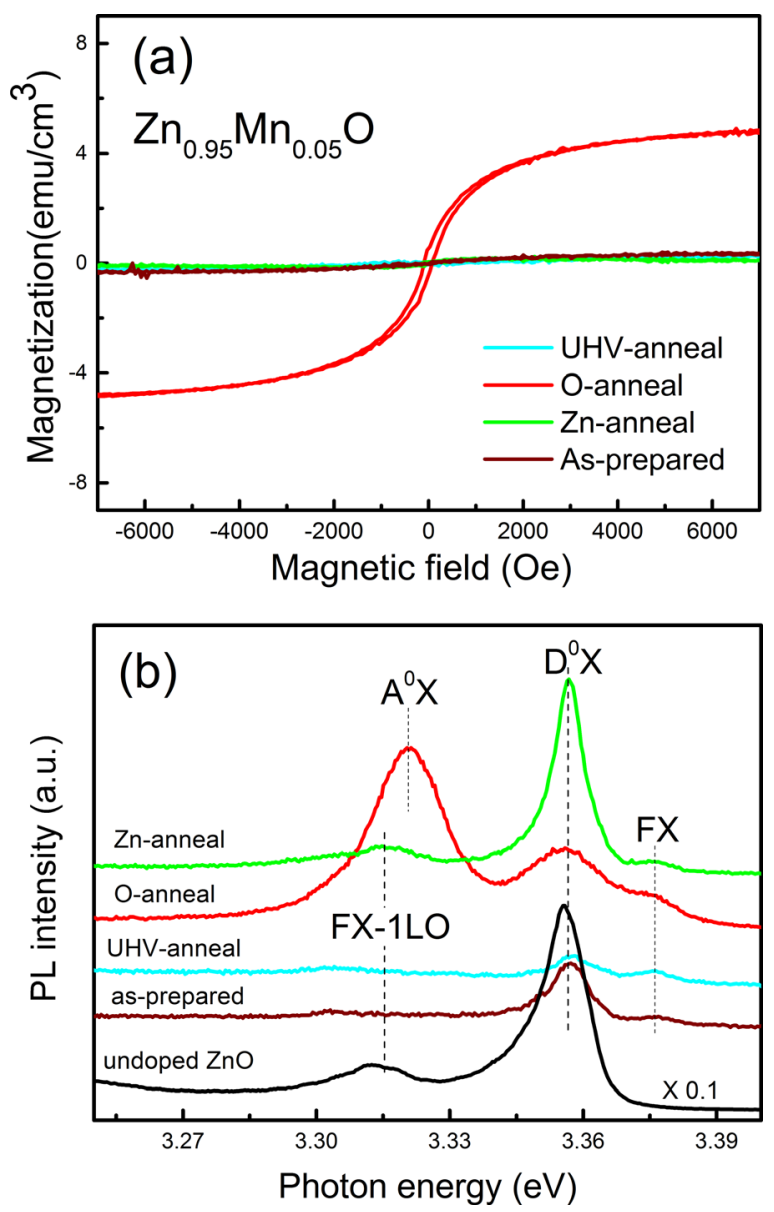

FIG. 3. (a) M-H curves of as-prepared, UHV-anneal, O-anneal, and Znanneal $\mathrm{Zn}_{0.95} \mathrm{Mn}_{0.05} \mathrm{O}$ films at RT. (b) Near band PL spectra at $5 \mathrm{~K}$ for asprepared, UHV-anneal, $\mathrm{Zn}$-anneal, and $\mathrm{O}$-anneal $\mathrm{Zn}_{0.95} \mathrm{Mn}_{0.05} \mathrm{O}$ epitaxial films, as well as undoped $\mathrm{ZnO}$ film for comparison. The dashed lines are guides to the eyes. recombinations of free exciton $(\mathrm{FX}),{ }^{21,22}$ neutral donorbound exciton $\left(\mathrm{D}^{0} \mathrm{X}\right),{ }^{21,23}$ neutral acceptor-bound exciton $\left(\mathrm{A}^{0} \mathrm{X}\right),{ }^{23,24}$ and the first replica of $\mathrm{FX},{ }^{25,26}$ respectively. The $\mathrm{PL}$ spectra clearly indicated the modulation of $\mathrm{D}^{0} \mathrm{X}$ and $\mathrm{A}^{0} \mathrm{X}$ emissions by annealing processing. The $\mathrm{A}^{0} \mathrm{X}$ emission is dominated in the $\mathrm{O}$-anneal film, whereas the $\mathrm{D}^{0} \mathrm{X}$ emission is dominated for as-prepared, UHV-anneal, and Zn-anneal films. In addition, the RT Hall effect measurements revealed that post-annealing treatments strongly influence the resistivity of the samples. All the films are n-type conduction. The carrier concentrations are $9.0 \times 10^{17} \mathrm{~cm}^{-3}, 2.1 \times 10^{18} \mathrm{~cm}^{-3}$, and $1.0 \times 10^{17} \mathrm{~cm}^{-3}$ for as-grown, $\mathrm{Zn}$-anneal, and O-anneal films, respectively. The Hall measurements indicated that the $\mathrm{O}$-anneal process reduces the n-type character of the material, which is consistent with the PL results. The above results revealed that the ferromagnetism activated by $\mathrm{O}$-anneal processing arises from the uncompensated acceptor defects, which is consistent with theoretical predictions ${ }^{27}$ and experimental results reported earlier. ${ }^{28,29}$ Without incorporating any additional chemical impurities, the most possible effect of O-annealing is the cancellation of native oxygen vacancies, which may reduce the n-type character of the material and eventually allow some previously compensated native acceptor defects to hybridize with $\mathrm{Mn}$ ions and mediate the ferromagnetic coupling.

Fig. 4(a) shows the Raman spectra of as-prepared and post-annealed $\mathrm{Zn}_{0.95} \mathrm{Mn}_{0.05} \mathrm{O}$ epitaxial films. In fact, Raman
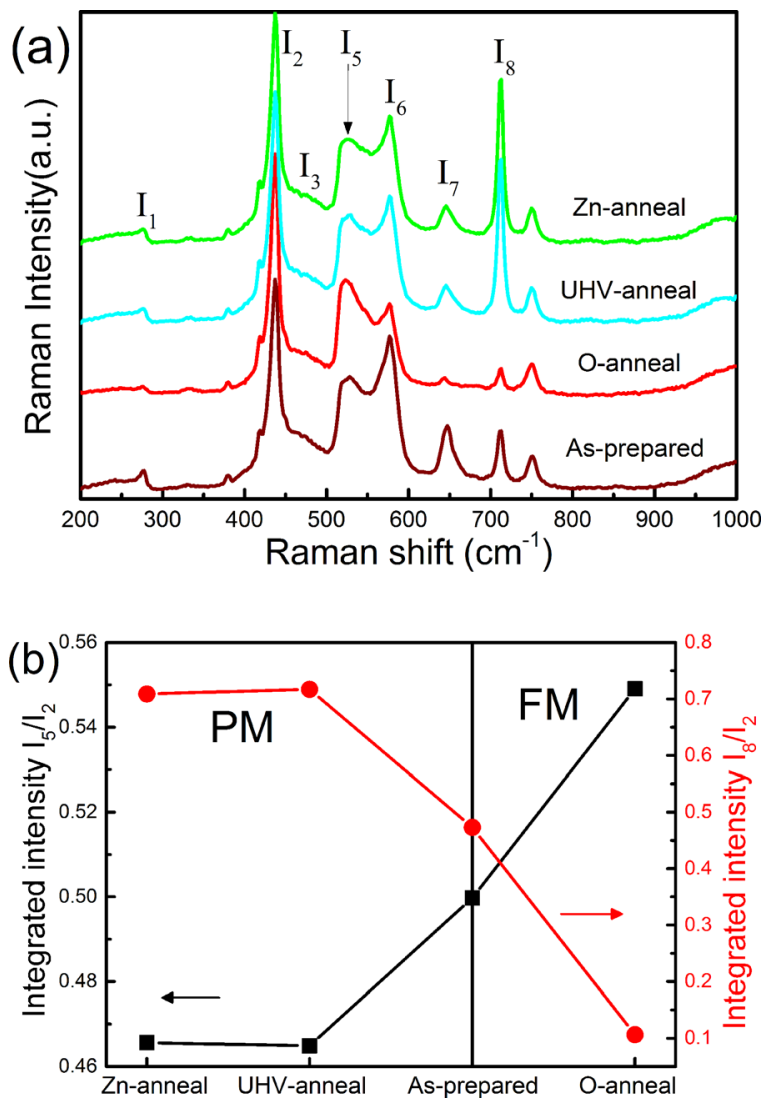

FIG. 4. (a) Raman spectra of as-prepared, O-anneal, UHV-anneal, and Znanneal $\mathrm{Zn}_{0.95} \mathrm{Mn}_{0.05} \mathrm{O}$ epitaxial films. (b) Integrated intensity of $\mathrm{I}_{5} / \mathrm{I}_{2}$ and $\mathrm{I}_{8} /$ $\mathrm{I}_{2}$ for as-prepared, $\mathrm{Zn}$-anneal, UHV-anneal, and $\mathrm{O}$-anneal $\mathrm{Zn}_{0.95} \mathrm{Mn}_{0.05} \mathrm{O}$ epitaxial films. 
scattering spectroscopy is very sensitive to the formation of secondary phases. It has been used as a powerful tool to detect many probable secondary phases in the host materials that may not be detectable by conventional XRD. ${ }^{30}$ Besides the general appearance of the phonon modes observed in asprepared samples, there are no additional modes attributed to the formation of magnetic secondary phases in post-annealed films. It indicates that post-annealed process did not introduce any secondary phase. It is interested that the integrated intensity of LVMs $\mathrm{I}_{5}$ and $\mathrm{I}_{8}$ are modulated by different annealing processing. By using Lorentz fitting, the integrated intensity of $\mathrm{I}_{5} / \mathrm{I}_{2}$ and $\mathrm{I}_{8} / \mathrm{I}_{2}$ for as-prepared, UHV-anneal, Znanneal, and $\mathrm{O}$-anneal $\mathrm{Zn}_{0.95} \mathrm{Mn}_{0.05} \mathrm{O}$ epitaxial films are shown in Fig. 4(b). The integrated intensity of $I_{8} / I_{2}$ is suppressed in O-anneal films, while it is enhanced in $\mathrm{Zn}$-anneal or UHV-anneal films. Reversely, the integrated intensity of $\mathrm{I}_{5} / \mathrm{I}_{2}$ is enhanced in O-anneal sample, while it is depressed in Zn-anneal or UHV-anneal samples. The competition of LVMs indicates that they are related not only to Mn dopants but also to the defects in the material. Moreover, the results from PL measurements reveal that $L V M I_{5}$ associate with acceptor defects, while the $\mathrm{LVM}_{8}$ associates with donor defects. The dominated native acceptor defects in $\mathrm{ZnO}$ films are Zinc-vacancy or interstitial-oxygen. First-principles calculation showed that Zinc-vacancy has lowest formation energy. ${ }^{31,32}$ In fact, Zinc-vacancy have been identified as the dominant compensating center in n-type $\mathrm{ZnO}$ by positron annihilation measurements, ${ }^{33}$ and they are also more favorable in oxygen-rich conditions. ${ }^{32}$ On another hand, the $\mathrm{O}_{\mathrm{i}}$ at the tetrahedral site is unstable ${ }^{32}$ and, spontaneously, relaxes through recombination with their vacancies upon thermal annealing. Therefore, Zinc-vacancy or their complexes are considered to be the dominant acceptor defects in our films. Among the defects behaved as donors, Oxygen-vacancy has the lowest formation energy, ${ }^{31}$ and is more favorable under our oxygen deficient growth condition. In addition, Zinc interstitials have high formation energy and diffuse fast due to their migration barrier as low as $0.57 \mathrm{eV} .^{32}$ They are easily annealed out under our thermal annealing condition with the temperature up to $800^{\circ} \mathrm{C}$. Consequently, $\mathrm{LVM} \mathrm{I}_{5}$ can be attributed to local vibration of Mn-(Zinc-vacancy) complexes, while $\mathrm{LVM} \mathrm{I}_{8}$ can be attributed to local vibration of Mn-(Oxygen-vacancy) complexes.

\section{Effects of (Mn, Co)-codoping}

To confirm the assignment of LVMs $\mathrm{I}_{5}$ and $\mathrm{I}_{8}$, we studied Co-doped and (Mn, Co)-codoped $\mathrm{ZnO}$ epitaxial films, which were grown under similar conditions. Codoping ${ }^{34,35}$ has been considered as a possible way to tailor the magnetic features of oxide magnetic semiconductors as a result of the existence of optimum structural dopant-defect configurations. Fig. 5 shows the M-H curves of $\mathrm{Zn}_{0.99-\mathrm{x}} \mathrm{Co}_{0.01} \mathrm{Mn}_{\mathrm{x}} \mathrm{O}$ epitaxial films with $\mathrm{x}=0,0.01,0.03$, and 0.05 . Clear hysteresis loops are observed in samples with $\mathrm{x}=0.03$ and 0.05 , which indicates that the ferromagnetism was switched on by introducing $1 \%$ Co. It is noticed that the $\mathrm{Zn}_{0.99} \mathrm{Co}_{0.01} \mathrm{O}$ and $\mathrm{Zn}_{1-\mathrm{x}} \mathrm{Mn}_{\mathrm{x}} \mathrm{O}$ epitaxial films are both paramagnetic. The fact that the saturated magnetization increases linearly with Mn content, as shown in

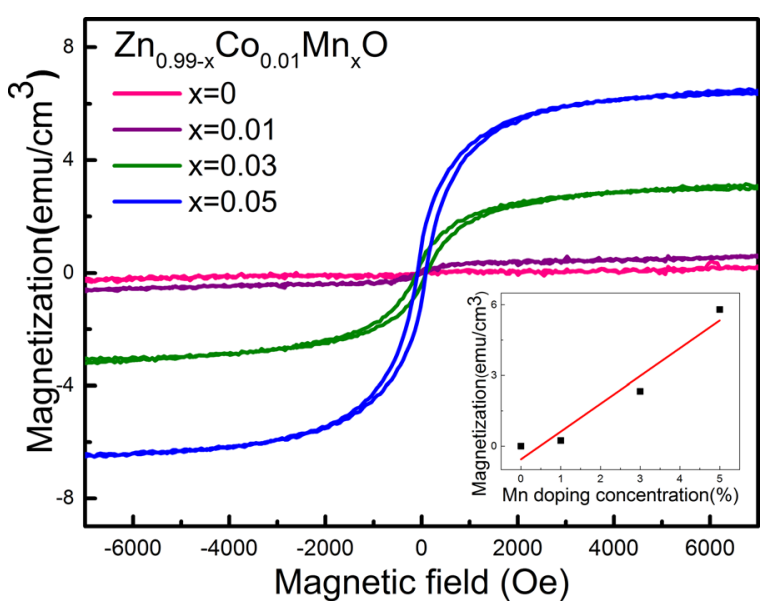

FIG. 5. M-H curves of $\mathrm{Zn}_{0.99-\mathrm{x}} \mathrm{Co}_{0.01} \mathrm{Mn}_{\mathrm{x}} \mathrm{O}$ films with $\mathrm{x}=0,0.01,0.03$, and 0.05. The inset shows the saturated magnetization as a function of $\mathrm{Mn}$ component.

the inset of Fig. 5, virtually eliminates the possibility of Co or cobalt oxide clusters being responsible for ferromagnetism. The ferromagnetic ordering in codoped samples is likely developed by the synergetic interactions. ${ }^{35}$ It can be described as dopant-defect hybridization, i.e., $\mathrm{Mn}^{2+}+\mathrm{Co}^{2+} \rightarrow \mathrm{Mn}^{2+}$ $\left.+h_{\text {acceptor }}^{+}\right)^{3+}+\left(\mathrm{Co}^{2+}+\mathrm{e}_{\mathrm{d} o \text { nor }}^{-}\right)^{+} \cdot 36,37$ When additional Co dopants were introduced, more $\mathrm{Mn}$ - acceptor complexes were activated with increasing of Mn content, thereby the ferromagnetism was enhanced with $\mathrm{Mn}$ content. In this regard, the effect of the codoping is similar to O-anneal processes. As a consequence, the same trend should also be observed in Raman spectra for $\mathrm{Zn}_{0.99-\mathrm{x}} \mathrm{Co}_{0.01} \mathrm{Mn}_{\mathrm{x}} \mathrm{O}$ films.

Fig. 6(a) shows the Raman scattering spectra of $\mathrm{Zn}_{0.99-}$ ${ }_{\mathrm{x}} \mathrm{Co}_{0.01} \mathrm{Mn}_{\mathrm{x}} \mathrm{O}$ epitaxial films. Figs. 6(b) and 6(c) show the integrated intensity of $\mathrm{I}_{5} / \mathrm{I}_{2}$ and $\mathrm{I}_{8} / \mathrm{I}_{2}$ as function of Mn content $\mathrm{x}$ for $\mathrm{Zn}_{1-\mathrm{x}} \mathrm{Mn}_{\mathrm{x}} \mathrm{O}$ and $\mathrm{Zn}_{0.99-\mathrm{x}} \mathrm{Co}_{0.01} \mathrm{Mn}_{\mathrm{x}} \mathrm{O}$ epitaxial films, respectively. Although the integrated intensity of $\mathrm{I}_{5}$ and $\mathrm{I}_{8}$ are both enhanced with increasing $\mathrm{Mn}$ contents, the integrated intensity of $\mathrm{I}_{5} / \mathrm{I}_{2}$ was enhanced, while the integrated intensity of $\mathrm{I}_{8} / \mathrm{I}_{2}$ is suppressed for the $\mathrm{Zn}_{0.99}$ ${ }_{\mathrm{x}} \mathrm{Co}_{0.01} \mathrm{Mn}_{\mathrm{x}} \mathrm{O}$ by introducing $1 \% \mathrm{Co}$. The enhancement of $\mathrm{I}_{5} /$ $\mathrm{I}_{2}$ and suppression of $\mathrm{I}_{8} / \mathrm{I}_{2}$ are consistent with the observation in O-anneal films as shown in Fig. 4, and further corroborate the assignments of $\mathrm{LVM} \mathrm{I}_{5}$ and $\mathrm{I}_{8}$. Our previous work indicated that the mode $\mathrm{I}_{9}$ is assigned to a cobalt-elemental sensitive mode. ${ }^{18}$ The intensity of mode $\mathrm{I}_{9}$ remains constant, which is consistent with the fixed concentration of Co (1\%).

\section{SUMMARY}

In summary, the magnetic, vibrational, and photoluminescence properties of high quality $\mathrm{ZnMnO}$ films grown by OPAMBE were studied. The ferromagnetism can be switched on in ways of oxygen annealing processing and introducing tiny Co. PL spectra of annealed samples indicated that the acceptor defects are dominant in O-anneal samples, whereas donor defects are dominant in other samples. Raman scattering spectra revealed two local vibrational modes (LVMs) associated with Mn dopants at 523 and $712 \mathrm{~cm}^{-1}$. The relative intensity of two LVMs clearly shows 

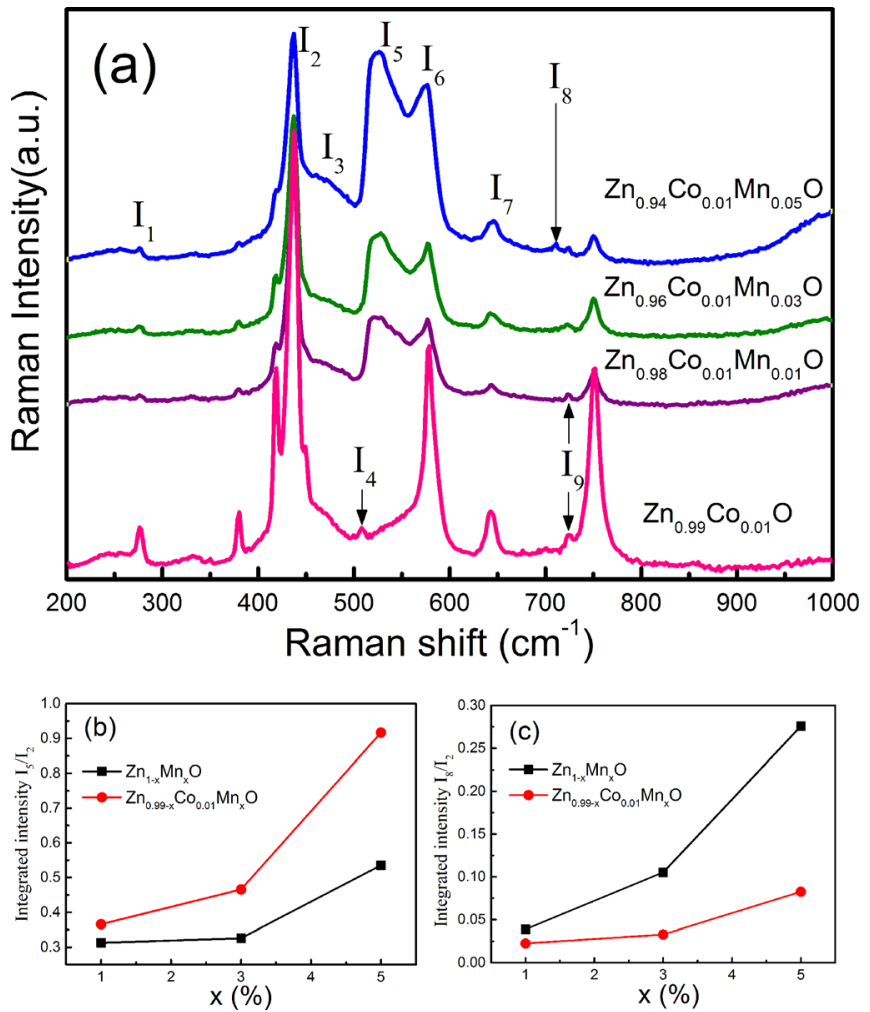

FIG. 6. (a) Raman spectra of $\mathrm{Zn}_{0.99-\mathrm{x}} \mathrm{Co}_{0.01} \mathrm{Mn}_{\mathrm{x}} \mathrm{O}$ epitaxial films with $\mathrm{x}=0.01,0.03$, and 0.05 , as well as the $\mathrm{Zn}_{0.99} \mathrm{Co}_{0.01} \mathrm{O}$ film. (b) Integrated intensity of $\mathrm{I}_{5} / \mathrm{I}_{2}$ as a function of Mn content $\mathrm{x}$ for $\mathrm{Zn}_{1-\mathrm{x}} \mathrm{Mn}_{\mathrm{x}} \mathrm{O}$ and $\mathrm{Zn}_{0.99}$ ${ }_{x} \mathrm{Co}_{0.01} \mathrm{Mn}_{\mathrm{x}} \mathrm{O}$ epitaxial films. (c) Integrated intensity of $\mathrm{I}_{8} / \mathrm{I}_{2}$ as a function of Mn content $\mathrm{x}$ for $\mathrm{Zn}_{1-\mathrm{x}} \mathrm{Mn}_{\mathrm{x}} \mathrm{O}$ and $\mathrm{Zn}_{0.99-\mathrm{x}} \mathrm{Co}_{0.01} \mathrm{Mn}_{\mathrm{x}} \mathrm{O}$ epitaxial films.

competitions arising from uncompensated acceptor to donor defects competition for ferromagnetic and nonmagnetic films. Our experimental results indicated that the LVM at $523 \mathrm{~cm}^{-1}$ is attributed to $\mathrm{Mn}$ - (Zinc-vacancy) complexes, and the LVM at $712 \mathrm{~cm}^{-1}$ is attributed to $\mathrm{Mn}-$ (Oxygen-vacancy) complexes.

\section{ACKNOWLEDGMENTS}

This work was financially supported by the State Key Project of Fundamental Research of China under Grant No. 2013CB922303, the NSF Grant Nos. 11374189 and 51231007, 111 Project B13029, Shandong Postdoctoral Grant No. 201303099, Research Grants from China Electronics Technology Group Corporation No. 46 Research Institute No. CJ20130304.

${ }^{1}$ U. Ozgur, D. Hofstetter, and H. Morkoc, Proc. IEEE 98, 1255 (2010).

${ }^{2}$ S. B. Ogale, Adv. Mater. 22, 3125 (2010).

${ }^{3}$ J. M. Coey, M. Venkatesan, and C. B. Fitzgerald, Nature Mater. 4, 173 (2005).
${ }^{4}$ W. Götz, N. M. Johnson, D. P. Bour, M. D. McCluskey, and E. E. Haller, Appl. Phys. Lett. 69, 3725 (1996).

${ }^{5}$ W. Limmer, W. Ritter, R. Sauer, B. Mensching, C. Liu, and B. Rauschenbach, Appl. Phys. Lett. 72, 2589 (1998).

${ }^{6}$ J. B. Wang, G. J. Huang, X. L. Zhong, L. Z. Sun, Y. C. Zhou, and E. H. Liu, Appl. Phys. Lett. 88, 252502 (2006).

${ }^{7}$ H. Zhong, J. Wang, X. Chen, Z. Li, W. Xu, and W. Lu, J. Appl. Phys. 99, 103905 (2006).

${ }^{8}$ B. Straumal, A. Mazilkin, S. Protasova, A. Myatiev, P. Straumal, G. Schütz, P. van Aken, E. Goering, and B. Baretzky, Phys. Rev. B 79, 205206 (2009).

${ }^{9}$ D. C. Kundaliya, S. B. Ogale, S. E. Lofland, S. Dhar, C. J. Metting, S. R. Shinde, Z. Ma, B. Varughese, K. V. Ramanujachary, L. Salamanca-Riba, and T. Venkatesan, Nature Mater. 3, 709 (2004).

${ }^{10}$ G. L. Liu, Q. Cao, J. X. Deng, P. F. Xing, Y. F. Tian, Y. X. Chen, S. S. Yan, and L. M. Mei, Appl. Phys. Lett. 90, 052504 (2007).

${ }^{11}$ F. J. Manjón, B. Marí, J. Serrano, and A. H. Romero, J. Appl. Phys. 97, 053516 (2005).

${ }^{12}$ R. Cuscó, E. Alarcón-Lladó, J. Ibáñez, L. Artús, J. Jiménez, B. Wang, and M. Callahan, Phys. Rev. B 75, 165202 (2007).

${ }^{13}$ J. T. Ji, A. M. Zhang, T. L. Xia, Q. Cao, G. L. Liu, D. Hou, and Q. M. Zhang, Phys. Rev. B 82, 014408 (2010).

${ }^{14}$ C. J. Cong, L. Liao, Q. Y. Liu, J. C. Li, and K. L. Zhang, Nanotechnology 17, 1520 (2006).

${ }^{15}$ K. Samanta, S. Dussan, R. S. Katiyar, and P. Bhattacharya, Appl. Phys. Lett. 90, 261903 (2007).

${ }^{16}$ M. A. Garcia, M. L. Ruiz-Gonzalez, A. Quesada, J. L. Costa-Kramer, J. F. Fernandez, S. J. Khatib, A. Wennberg, A. C. Caballero, M. S. MartinGonzalez, M. Villegas, F. Briones, J. M. Gonzalez-Calbet, and A. Hernando, Phys. Rev. Lett. 94, 217206 (2005).

${ }^{17}$ C. B. Azzoni, M. C. Mozzati, P. Galinetto, A. Paleari, V. Massarotti, D. Capsoni, and M. Bini, Solid State Commun. 112, 375 (1999).

${ }^{18}$ Q. Cao, S. He, Y. Deng, D. Zhu, X. Cui, G. Liu, H. Zhang, S. Yan, Y. Chen, and L. Mei, Curr. Appl. Phys. 14, 744 (2014).

${ }^{19}$ S. Kolesnik and B. Dabrowski, J. Appl. Phys. 96, 5379 (2004).

${ }^{20}$ T. C. Droubay, D. J. Keavney, T. C. Kaspar, S. M. Heald, C. M. Wang, C. A. Johnson, K. M. Whitaker, D. R. Gamelin, and S. A. Chambers, Phys. Rev. B 79, 155203 (2009)

${ }^{21}$ A. Teke, Ü. Özgür, S. Doğan, X. Gu, H. Morkoç, B. Nemeth, J. Nause, and H. Everitt, Phys. Rev. B 70, 195207 (2004).

${ }^{22}$ W. Y. Liang and A. D. Yoffe, Phys. Rev. Lett. 20, 59 (1968).

${ }^{23}$ F. X. Xiu, Z. Yang, L. J. Mandalapu, and J. L. Liu, Appl. Phys. Lett. 88, 152116 (2006).

${ }^{24}$ Z. Yang and J. L. Liu, J. Vacuum Sci. Technol. B 28, C3D6 (2010).

${ }^{25}$ F. Jiang and J. Zhang, Appl. Phys. Lett. 98, 181912 (2011).

${ }^{26}$ C. Klingshirn, Phys. Status Solidi B 71, 547 (1975).

${ }^{27}$ Q. Wang, Q. Sun, P. Jena, and Y. Kawazoe, Phys. Rev. B 70, 052408 (2004).

${ }^{28}$ K. R. Kittilstved, N. S. Norberg, and D. R. Gamelin, Phys. Rev. Lett. 94, 147209 (2005).

${ }^{29}$ D. Rubi, J. Fontcuberta, A. Calleja, L. Aragonès, X. Capdevila, and M. Segarra, Phys. Rev. B 75, 155322 (2007).

${ }^{30}$ X. Wang, J. Xu, X. Yu, K. Xue, J. Yu, and X. Zhao, Appl. Phys. Lett. 91, 031908 (2007).

${ }^{31}$ A. F. Kohan, G. Ceder, D. Morgan, and C. G. Van de Walle, Phys. Rev. B 61, 15019 (2000).

${ }^{32}$ A. Janotti and C. G. Van de Walle, Phys. Rev. B 76, 165202 (2007).

${ }^{33}$ F. Tuomisto, V. Ranki, K. Saarinen, and D. C. Look, Phys. Rev. Lett. 91, 205502 (2003).

${ }^{34}$ N. N. Lathiotakis and M. Menon, Phys. Rev. B 78, 193311 (2008).

${ }^{35}$ A. N. Andriotis and M. Menon, Phys. Rev. B 87, 155309 (2013).

${ }^{36}$ L. B. Duan, G. H. Rao, Y. C. Wang, J. Yu, and T. Wang, J. Appl. Phys. 104, 013909 (2008)

${ }^{37}$ K. R. Kittilstved, W. K. Liu, and D. R. Gamelin, Nature Mater. 5, 291 (2006). 